\title{
CULTURAL INTERMEDIARIES AND THE MEDIA
}

\author{
Jennifer Smith Maguire and Julian Matthews \\ Citation: \\ 2010. Cultural Intermediaries and the Media. Sociology Compass. 4/7 (2010): 405- \\ 416.
}

\begin{abstract}
:
This article provides an introduction to, and makes a case for, cultural intermediaries as an entry point for the study of media and cultural production. We offer a strategic parsing of the conceptual foundations provided by Bourdieu with regard to cultural intermediaries and the media, loosely organized in terms of where they are located (working in media); the means of accomplishing their role (working with media); and their economic role in promoting consumption (the work of mediation). We then follow the translation of the concept from Bourdieu to a cultural economy approach that is concerned with the material practices involved in the formation of value. A review and comparison of substantive findings from a range of cultural economic case studies of cultural intermediary occupations serves as an introduction to a threefold approach that might guide future studies of occupations in cultural industries, in terms of: historicizing occupations, material practices, and assessments of impact. Finally, we conclude with a claim for the utility of 'cultural intermediaries' as a way to think about cultural production, and highlight areas in which work remains to be done.
\end{abstract}

\section{Introduction}

Since the early 1990s, considerable social scientific attention has been directed at the character, roles and implications of the service class in the context of contemporary consumer economies (e.g. Lash and Urry 1994; Florida 2002). Against the backdrop of expanding higher education, growing service industries marked by feminization and precariousness, the globalization of commodity chains concentrating the functions of design, branding and marketing in developed labour markets, and the increasing centrality of 'culture' (images, experiences, ideas) to economies, an emergent body of scholarly research explores the significance of cultural producers. One stream within this work revolves around the notion of 'cultural intermediaries': producers of symbolic goods and services, to whom Pierre Bourdieu (1984) ascribes a significant role in the reproduction of consumer economies.

Despite the explicit connection in Bourdieu's original formulation between cultural intermediaries and the media, the use of the concept in scholarly research on media occupations remains underdeveloped. This article provides an introduction to, and makes a case for, cultural intermediaries as an entry point for the study of media and cultural production. Our overview chimes with recent considerations of how the 
political economic study of cultural production has focused on structures and organizational flows of power at the expense of an adequate account of the contested, everyday practices of the agents of cultural production (e.g. Garnham 2005; Havens et al 2009; cf. Caldwell 2008; Hesmondhalgh 2006). Bourdieu's concern with the cultural worker is certainly not unique. Sociology of culture and cultural studies research has also focused on the practices of cultural producers (for useful reviews of which, see Cook 2006; Havens et al 2009). To a much greater extent than Bourdieu (who was primarily working from large-scale survey data), such research foregrounds issues of agency and negotiation in ethnographic examinations of producers in such fields as television (D'Acci 1994; Havens 2006; Tinic 2005) and advertising and marketing (Davila 2001; Lotz 2007; Sender 2004). Taking up this focus on the cultural worker and extending beyond Bourdieu's initial formulation, while employing an ethnographic sensitivity to lived experience and material practices, have been a number of 'cultural economic' (du Gay and Pryke 2002) examinations of producers in fields such as fashion (e.g. Entwistle 2006), advertising (e.g. Cronin 2004), branding (e.g. Moor 2008), and lifestyle magazines (e.g. Gough-Yates 2003).

The article proceeds, first, by highlighting the conceptual foundations provided by Bourdieu. We then map the translation of the concept from Bourdieu to a cultural economy approach. Setting out three fronts on which analyses of cultural intermediaries might proceed, we review key findings from a range of cultural economic case studies. Finally, we conclude with a claim for the utility of 'cultural intermediaries' as a way to think about cultural production, and highlight areas in which work remains to be done.

\section{Bourdieu on Cultural Intermediaries}

The point of departure for discussions of cultural intermediaries is typically Bourdieu's Distinction: A Social Critique of the Judgment of Taste (1984). Drawing on social survey data and qualitative vignettes from France in the 1960s and early 1970s, Bourdieu analyses patterns in the consumption practices and preferences of socio-occupational groups. In doing so, he suggests how 'taste' is a contested terrain on which battles for legitimacy and distinction are fought. Of particular interest are the petite bourgeoisie, and especially that fraction he calls the 'new' petite bourgeoisie (1984: 354-65, passim), of which cultural intermediaries are members and exemplars.

Below, we offer a strategic parsing of Distinction with regard to cultural intermediaries and the media, loosely organized in terms of where they are located (working in media); the means of accomplishing their role (working with media); and their economic role in promoting consumption (the work of mediation).

Working in media. Cultural intermediaries may be defined, descriptively, by their occupations, which are largely located in the cultural industries, including the media. Bourdieu highlights (1984: 359), as hallmarks of the new petite bourgeoisie, occupations involved in: 
presentation and representation (sales, marketing, advertising, public relations, fashion, decoration and so forth) and in all the institutions providing symbolic goods and services. These include the various jobs in medical and social assistance... and in cultural production and organization (...radio and TV producers and presenters, magazine journalists).

Within that large (and internally differentiated) new petite bourgeois fraction, cultural intermediaries are most typically 'the producers of cultural programmes on TV and radio or the critics of 'quality' newspapers and magazines and all the writerjournalists and journalist-writers' (1984: 325).

As a working definition, however, such a description has come under criticism. First, the assertion that these are 'new' occupations is problematic (Nixon and du Gay 2002: 497), if only because - despite technological advancements and changesmany of the occupations, their industries and the broader work of promoting consumption have long histories (e.g. McFall 2002, 2004). Second, the narrow reduction of cultural intermediaries to critics and commentators has created confusion, because the work of mediating cultural forms applies to a broader range of occupations, both within and beyond the petite bourgeoisie (new or otherwise) (Hesmondhalgh 2006: 226-7; Nixon and du Gay 2002: 498).

Working with media. Bourdieu highlights 'control over the mass media' (1984: 325) as a distinguishing characteristic of cultural intermediaries. Here, however, the focus is less on media occupations per se, and more on how cultural intermediaries use the media to accomplish their pedagogical work of shaping consumer tastes, as tools for the dissemination of their cultural wares and middle-brow culture more generally. This has radical potential, as mass media forms make possible the delivery of (a version of) legitimate culture into the private sphere of those normally excluded (1984: 33), be it a television presentation of an opera (the thing itself), or a popular discussion of opera on a television culture programme (words about something, as a substitution for the thing itself; 1984: 365).

It is not only that cultural intermediaries use media to accomplish their promotional work, but that in doing so they are an effect of and contributor to the corporatization of the media (cf. Hesmondhalgh 2006) and other cultural industries, which are increasingly intent on market growth, profitability and deference to ratings, audience circulation statistics and so forth. In the search for audiences and consumer markets, the world of mass production increasingly co-opts aspects of legitimate, restricted culture in order to lend cachet, legitimacy, value and so forth (Bourdieu 1996). The success of such strategies encourages an upward cycle of co-optation and commercialization. The cultural intermediary is the agent and mass media the conduit for the strategic migration and translation of 'restricted' culture into the field of large-scale production (Bourdieu 1984: 583; 1996).

Claims about the pedagogical work of cultural intermediaries are couched, more generally, in Bourdieu's view of the media as an indirect cultural mechanism for the reproduction of the social order. The media and its producers contribute to a 'diffuse 
education' (Bourdieu and Passeron 1977) that shapes tastes and dispositions. Hence, Bourdieu is concerned with the role of cultural intermediaries in shaping tastes for not only particular cultural goods, but also for particular ways of life.

The work of mediation. Beyond describing their location in cultural industries and their work in media production, however, Bourdieu offers a more useful, conceptual definition of cultural intermediaries as those involved in mediating between the production of cultural goods and the production of consumer tastes (1984: 230). For example, critics and commentators write, talk and present about cultural forms as a way to popularize them, assisting in the 'objective orchestration...of the fields of production and that of the field of consumption' (1984: 230; see also 232, passim). In this, petite bourgeois cultural intermediaries are closely aligned with their bourgeois counterparts ('the directors and executives of firms in tourism and journalism, publishing and the cinema, fashion and advertising, decoration and property development'; 1984: 310-11), whose lead they follow. If the bourgeois cultural intermediaries are the vanguard taste makers, then the petite bourgeois cultural intermediaries are responsible for selling those tastes as widely as possible. (However, recent work on cultural intermediaries has largely lost sight of the dynamics between the established and new fractions of cultural intermediaries.)

Thus, cultural intermediaries are defined by their role in mediating between production and consumption. They have a broadly pedagogic function, shaping the perceptions and preferences of consumers in order to mobilize their actions along desired routes. In this, they effect a 'symbolic imposition' (1984: 362), framing particular cultural products as legitimate and, thus, as valuable. They contribute to the "production of the value of the work or, what amounts to the same thing, of the belief in the value of the work' (Bourdieu 1996: 229). In short, they add value.

Forms of legitimate culture do not require cultural intermediary interventions; their cultural value is already assured through established hierarchies and authorities.

Rather, cultural intermediaries work within the sphere of the legitimisable (Bourdieu et al 1990) to canonize the 'not-yet-legitimate' (1984: 326) (and thus not (yet) monopolized by the dominant class). They do this via the mobilization of both established, legitimate culture and the forms of media at their disposal. By surrounding the not-yet-legitimate with the established signs of authority and credibility, cultural intermediaries help to frame certain choices as more desirable. In doing so, they do not divulge legitimate culture (which is ultimately impossible; 1984: 326), but rather expand the content of middle-brow culture by popularizing (and thus, for Bourdieu, rendering mediocre) legitimate culture.

The work of mediation is bound up with the subjective dispositions of cultural intermediaries, in whom Bourdieu detects a particular harmony between the personal and the occupational (1984: 240, 365). This harmony manifests in the peculiar resource of sincerity, in that cultural intermediaries offer themselves as 'role models and guarantors' (1984: 365) — and this is facilitated because they are of the class of consumer to whom they direct their work. That is, cultural intermediaries are both 
cultural producers and their own ideal consumers. As such, Bourdieu regards the new petite bourgeoisie as ideal 'needs merchants', both in that they are convincing (they 'sell so well because they believe in what they sell'; 1984: 365) and that they are always selling — beyond a specific good or service — an entire lifestyle or 'art of living' (1984: 366). In a speculative discussion, Bourdieu suggests cultural intermediaries - and the new petite bourgeoisie generally — are the 'transmission belt' for the ethical retooling of the new economy, embodying and promoting an ethos of fun and pleasure in order to produce the need for their product and, by extension, themselves (1984: 359, 365).

In summary, there are several points of intersection between cultural intermediaries and the media, in terms of: occupations located in the media industries; producers of media content with a particular pedagogical mission; mediators of taste and billboards for a prescribed lifestyle. Moving forward from Bourdieu, we find that the focus on media occupations per se has been superseded by the more inclusive notion of those mediating between production and consumption (Negus 2002), and that a host of cultural economic case studies call attention to the diverse strategies and devices (of which mass media is but one) employed in the promotion of consumption.

\section{From Bourdieu to Cultural Economy}

Bourdieu's discussion of cultural intermediaries and the new petite bourgeoisie rests upon the assumed emergence of a 'new economy... whose functioning depends as much on the production of needs and consumers as on the production of goods' (1984: 310). Such an economy is intimately concerned with the coordination of supply and demand, and thus with the work of those - like cultural intermediarieswho are charged with knowing, shaping and directing consumer needs and desires. More broadly, much scholarly attention has been directed at the perceived shift in the West over the $20^{\text {th }}$ century from production- to consumption-oriented societies, in which identity and status are regarded less as expressions of one's work role and more as outcomes of one's consuming habits. Such arguments are often attended by the suggestion that culture and economy - typically considered as normatively distinct spheres of activity - are increasingly blurred in contemporary society, as culture (in the form of images, information, services, signs) becomes more central to the economy, and the economic logic of instrumentality and accumulation comes to pervade cultural, symbolic life (e.g. Featherstone 1991; Lash and Urry 1994).

However, claims that cultural intermediaries are part of a radically new organization of economic and cultural life have been contested (e.g. du Gay 2004; McFall 2004). Drawing from the anthropology of science and techniques (AST), actor-network theory (ANT) and Foucault's work on governmentality (McFall 2004: 63, 82-3), a cultural economy approach rejects the position that there has been a fundamental break with the past, out of which has emerged a 'new' hybridization of culture and economy. Rather, a cultural economy perspective is concerned with 'the ways in which objects and persons are constituted through the discourses and techniques 
used to describe them and to act upon them' (du Gay 2004: 100). Cultural economic analyses displace the question of the blurring or hybridization of culture and economy with the question of how culture and economy are mutually produced through material practices.

Amin and Thrift (2004: xviii) offer an overarching definition of cultural economy as 'being concerned with the processes of social and cultural relations that go to make up what we conventionally term the economic.' They trace a development from a general cultural turn in which culture was 'added to' political economic analyses, to increasingly nuanced understandings of how 'culture' and 'economy' are mutually implicated and produced. To escape the reifying effects of using the very categories of 'economy' and 'culture,' Amin and Thrift (2004: xiv-xv) map out cultural economy as an 'analysis of the steps through which economic quantities and qualities are formed. ... [I]t is an attempt to identify the varied impulses and articulations through which value is formed, added, and circulated.' Building on Bourdieu's concern with how cultural intermediaries are implicated in the production of 'the belief in the value of the work' (1996: 229), cultural economy research is thus concerned with the creation of value. Hence, the interest in cultural intermediaries, who perform the 'relational work' (Cochoy 2003 in du Gay 2004: 100) between production and consumption, economy and culture. To return to points of intersection between cultural intermediaries and the media, the issue is not whether cultural intermediaries are located in the media and/or work with media, but how they accomplish the 'qualification of products' (Callon et al 2002: 196) through particular, material practices.

Given its emphasis on the interconnections of culture and economy in practice, cultural economic analyses engage in specific, contextual studies of practices and techniques that constitute the promotion of consumption: 'the ways in which different sorts of consumer conducts are mobilised, motivated and distributed through specific commercial actions and devices' (du Gay 2004: 100; see also Miller and Rose 1997). Of interest are the social, technical and performative skills, as well as subjective dispositions, called upon by cultural intermediaries in the course of identifying and inscribing notions and perceptions of quality along the commodity chains of cultural goods and services, from product design (du Gay et al 1997: 62) to customer service interactions (Pettinger 2004). As such, this work is concerned with day-to-day practices, types of knowledge, attitudes and agendas, and thus employs interviews, field observation and other ethnographic methods, as well as archival and historical research, to explore cultural intermediaries' lived experiences and roles in economic and cultural life (Nixon and du Gay 2002: 498).

Having set out the broad, theoretical concerns and methodological approaches, we now turn to an overview of some of the substantive findings from cultural economic analyses of cultural intermediary occupations. This research has spanned such fields as advertising (Cronin 2004; McFall 2004; Nixon 2003; Soar, 2000); magazine publishing (Crewe 2003; Gough-Yates 2003); book retailing (Wright 2005); fashion design and retail (Entwistle 2006; Pettinger 2004; Skov 2002); and physical fitness 
(Smith Maguire 2008). Below, we use Moor's (2008) examination of branding consultants as an exemplar of such research, the discussion of which permits both a consideration of related case study findings, and an introduction to a three-fold approach that might guide future studies of occupations in cultural industries. Following Nixon and du Gay (2002), Moor examines branding consultants on three fronts, each building from Bourdieu's (1984) initial formulation, in terms of: historicizing occupations, material practices, and assessments of impact.

Historicizing occupations. The first front on which to consider cultural intermediaries is historical, as the basis on which to assess both the claim of 'newness' for cultural intermediaries (and, by extension, the new petite bourgeoisie), and the specific, historical context for their emergence and development. Strictly speaking, cultural intermediary work is not new; it is a manifestation and extension of middle class work more generally: work that intervenes between production and consumption. While there has been an increase in Western societies since the 1960s in the scales of occupations involving information, images and knowledge, these occupations are not necessarily new, nor are they uniformly expanding in number (Nixon and du Gay 2002: 497). In the case of branding consulting, Moor (2008) traces the emergence of the occupation in the US and UK to the late 1980s, within the field of industrial design, which can be traced back to the 1930s. More broadly, Moor connects the occupation's development with the intensification of attention to design, aesthetics and taste in the reproduction of late capitalist economies since the mid- $20^{\text {th }}$ century.

Attention to the development and professionalization of cultural intermediary occupations brings to light the ways in which the content of an occupation becomes codified and routinized. Considering branding, for example, the formalization of principles for connecting brand values to particular colours or materials - what is known as 'product semantics' — can be traced to the 1980s (Julier 2000 in Moor 2008: 419). Similarly, Moeran (1996: 60) refers to the 'system of conventions' through which advertising creatives in Japanese advertising agencies make sense of and coordinate with other advertising sub-groups, such as account managers; and Smith Maguire's (2008) examination of personal trainers highlights occupational conventions, such as a vocational attitude, that are endorsed through specialized practitioner publications. These insights are significant in that they counter claims about radically new forms of work in post-Fordist economies with empirical insight into the sort of deeply-entrenched normative conventions and occupational 'formulae' (Negus, 2002: 510) and 'habitii' (McFall 2004: 73) that structure (but do not determine) cultural intermediaries' work.

While the emergence of branding consultants may coincide with the mid- $20^{\text {th }}$ century, other case studies bring to light longer-term timelines. McFall (2002), for example, looks back to the start of the $19^{\text {th }}$ century to trace the emergence of advertising agents and their early links to artistic and literary circles, and notes that their occupation status and skills were increasingly formalized even by the early $20^{\text {th }}$ century. This variation in historical development underlines the need to treat cultural 
intermediation as an internally differentiated category: there is no one developmental trajectory for these occupations. Sensitivity is required to assess the lines of continuity and discontinuity across cases, in terms of the political, economic and social factors that contextualize moments of emergence, the pace of expansion or the motivation for the formalization of conventions for different cultural intermediary occupations.

Material practices. The second front on which to consider cultural intermediaries concerns the material, practical accomplishment of their work. Attention is given to the various and intertwined strategies and attitudes that make up cultural intermediaries' objective practices and subjective outlooks — what du Gay (2004: 100) groups as 'devices and dispositions.' Foci for research include, but are not limited to, occupational tools, codes, techniques and criteria, as standardized through training programmes and in textbooks, and manifest (and modified) in their actual application; and the dispositions, rationalities, motivations and aspirations expressed by cultural intermediaries and codified in their training programmes. On such a basis (as with the historicizing of the occupations), there can then be a grounded assessment of the similarities and differences within and across cultural intermediary occupations, thereby countering an undifferentiated, bloated notion of cultural intermediaries that has troubled some commentators (e.g. Hesmondhalgh 2006).

On this second front, Moor (2008) draws on interviews with eight London-based advertising, branding and communications professionals to identify several devices by which branding consultants accomplish their task of translating abstract values into material form. These tools include design audits, research on company-own and consumer perceptions of the brand, and the creation of design solutions that bring colours, materials, typography, music and so forth into line with brand values. The devices and strategies employed reflect the occupation's dual goals of augmenting products via brand values and shaping consumer tastes for those values. Unlike other promotional agents (such as those working in advertising), brand consultants regard a company's entire material presence as media, from the font used on stationary to the outfits worn by representatives at trade shows, and thus the devices employed reflect the 'extended spatial scope' (2008: 415) of the occupation, and in turn help redefine what counts as media from a promotional point of view.

Devices to add value, however, will differ between cultural intermediary occupations, relative to the scope and object of their domain. For example, Entwistle focuses on the case of fashion buyers, drawing on interviews and participant observation in a high end retailer in London to explore how these individuals are 'active in defining, shaping, transforming, qualifying and requalifying products' (2006: 704). In the most straightforward sense, fashion buyers add value by filtering what goods make it to market: Entwistle highlights how buyers' selections are based on judgements of an item's shape, colour and feel, alongside knowledge of its saleability based on notions of taste, trends and fashionability in a particular retail context (2006: 713). (For an interesting reversal of perspective, Skov's (2002) work considers the experiences of Hong Kong fashion designers, whose access to the 
marketplace is mediated by buyers' conceptions of what is marketable.) In addition, buyers add value through the 'pedagogic role of store placement' (2006: 715):

consumers are encouraged to regard an item in a particular way through strategies of product organization and display (e.g. where it is located within the store relative to other high status goods).

Returning to the case of branding consultants, Moor's research suggests that particular dispositions or forms of subjective knowledge are the precondition for identifying and implementing appropriate value-adding devices. Of note are branding consultants' sensitivity to aesthetic content and consistency, their mentality that assumes 'abstract brands and values can be expressed through particular materials' (2008: 419), and their experiential outlook on brands as total, immersive entities (2008: 416). It is not that branding consultants-or cultural intermediaries generally - have a monopoly on such dispositions. Indeed, sociology of consumption research has suggested that individuals, broadly, have a quest for aesthetic consistency (e.g. McCracken 1988) and the experiential qualities of consumption (e.g. Campbell 1987). Nevertheless, cultural intermediaries are unusual in that such dispositions can be strategically honed and deployed in the formation of value (for the promoted product, and cultural intermediaries themselves).

Furthermore, branding consultants make claims to expertise based on membership in an elite 'cult of creativity' (Moor 2008: 422) and possession of specialized knowledge and cultural capital that accrue from education, professional experience and personal biography. Similarly, Mellor's (2008) consideration of research on Arab journalists highlights how a command of other languages and foreign travel experience act as capital, supporting claims for professional credibility; and Wright's (2005) study of book selling reveals how bookshop workers rely on institutional and embodied cultural capital to assert their difference from, and thus superior cultural authority over, other retail workers. These examples, among many, are suggestive of an exceptionalist disposition for cultural intermediaries, through which they mark out their difference from other cultural producers and service workers engaged in comparable tasks. It is the exceptionalist disposition that converts cultural intermediaries themselves into devices, in two, related, ways.

First, cultural intermediaries become devices themselves in the sense that their biographies, attitudes and embodied capital serve as occupational resources and guarantors of credibility. For example, comparing their research on creative workers in the advertising and magazine publishing fields, Nixon and Crewe (2004: 131) note how such occupations disrupt "established divisions between "work" and "leisure" given the emphasis placed on socializing as a platform for accruing valuable social and cultural capital. Credibility as a creative, in short, required a metropolitan lifestyle (Nixon and Crewe 2004: 138), in much the same way as credibility as a personal trainer draws heavily on personal physique (Smith Maguire 2008), competence as a fashion retailer is read off of personal appearance (Pettinger 2004), aesthetic authority as a fashion designer is evidenced in personal lifestyle and 
home décor (Rocamora 2002), and reliability as an advice columnist is accomplished through the representation of a sincere persona (McKay 2008).

Second, arising from their particular dispositions (shaped through biography, class, age, sexuality and so forth) is the peculiar capacity of cultural intermediaries to serve as 'proxy consumers' (Ennis 2005 in Moor 2008: 422). For example, Moor discusses consultants' ambivalent attitude towards market research, often relying on their own preferences in assessing what 'works' for a brand strategy. Expertise in the form of a peculiar sensitivity to the market lies in consultants' capacity to identify with consumers, often thanks to sharing the same demographic profile (2008: 422), thereby making the market knowable and, ideally, predictable. In short, branding consultants are valuable to the extent to which they can read (and, in cases, typify) the target market.

Similarly, in the British 'lads mags' magazine industry, Crewe (2003: 183) explains how editorial figures 'were all instinctive in technique' and their 'identities, resources and ambitions were perhaps unusually important in imprinting their titles.' Editorial work in this sense involves the inseparable connection between work and non-work, and the overlapping of personal interests and preoccupations and professional expertise (2003: 193). Cultural intermediaries' personal experiences as consumers, for instance, are essential to their ability to 'read the market' and construct a sense of the ideal consumer (Gough-Yates 2003; Nixon 2003; Soar 2000). An ability to read the market on the basis of personal subjective knowledge (capital) is therefore the source of their expertise. Bearing these examples in mind, it becomes clear that the role of cultural intermediaries cannot be reduced to the routinized strategies found in textbooks or the findings of consumer research. Their claims for the uniqueness - indeed, indispensability - of their professional input speaks to the inseparability of devices and dispositions in practice.

Assessing impact. Building on the concerns outlined above, the third front on which to consider cultural intermediaries concerns the occupation's actual impact on the processes of value formation. This requires attention to the flow of advice, consequences of decisions and ongoing qualification of goods. On this basis, it is possible to provide a realistic assessment of the cultural economic significance of cultural intermediaries, and thus temper grand claims regarding their role as the 'transmission belt' (Bourdieu 1984: 365) of a new consumer economy.

On this third front, Moor (2008: 420) assesses the impact of branding consultants with reference to their capacity to:

first identify various qualities, values and ideas that will be meaningful and recognizable to a specified target audience, and then to find or create a series of replicable design features that will reliably convey these preferred ideas and associations in visual and material form.

Working from this definition of the occupation, Moor can then trace the impacts of branding consultancy, including the content of brand campaigns, related product innovation and the creation of company databases and manuals. In the same way by 
tracing material practices, other studies highlight the material results of, and inherent constraints on, the cultural authority of cultural intermediaries, from determining a retailer's purchase, to framing a customer's impression, of fashion stock (Entwistle 2006; Pettinger 2004); or from making consumers' anxieties and desires intelligible to producers, to making producer values coherent to consumers (Cronin 2004; Moor 2008).

Beyond their concrete consequences, Moor (2008: 409) also nods to a broader significance of branding consultants 'in the service of governance and forms of social organisation.' Through the interplay of devices and dispositions, branding consultants play a role, more generally, in the orchestration of production and consumption, through the creation of 'reliable' pathways between product attributes and perceived consumer desires. This assertion rests on an understanding of marketing as a governmental technology in keeping with contemporary power relations (Foucault 1991), which is directed at 'mobilizing' consumers by connecting their perceived desires and anxieties with product attributes so as to encourage the enactment of their freedom within the marketplace in appropriate ways, and thereby (ideally) accomplishing a seamless flow between supply and demand (Miller and Rose 1997; Zwick et al 2008). To study cultural intermediaries such as branding consultants is thus to study key agents charged with the 'governmental' mobilization of consumers. Thus, assessments of impact may look beyond the formation of value to the role of cultural intermediaries in the reproduction of contemporary social orders.

\section{Conclusion}

In the article, we have offered an introduction to the theoretical foundations and elaborations of the concept of cultural intermediaries, and reviewed empirical findings arising from its application in a range of cultural economy case studies. Drawing parallels between various case studies provides a clear demonstration of the complexity of the concept. Cultural intermediaries are not a monolithic occupational class; they are internally stratified along a number of lines, including historical development, associated levels of cultural authority and social prestige, and the differing forms and degrees of aesthetic labour and cultural capital required to accomplish their work in the formation of value.

Furthermore, we have sought to demonstrate that cultural intermediaries are 'good to think with,' throwing up a range of empirical and theoretical questions about the nature and import of their material practices. Thus, we suggest that cultural intermediaries are a useful, if as yet underutilized, entry point to the study of media. While not unique in foregrounding the practices and processes of production, the cultural economic approach has a number of benefits. By focusing on the cultural worker, such research necessarily is attentive to issues of power, agency and negotiation, to the material (and quotidian) practices and conventions that contour modes of work, and to the unintended outcomes and conflicts that arise when various forms of mediation intersect. 
In concluding, we note with Entwistle (2006: 707) that rather more attention has centered on cultural intermediaries' identities and lifestyles at the expense of close investigation of the actual processes of mediation. The specific practices and processes of how value is formed and added to cultural goods, the interconnections of various intermediaries operating in and across various fields, and how such cultural work can be conceptualised generally remain fertile areas for further study, discussion and debate.

Bourdieu's (1984) formulation of cultural intermediaries, if often speculative, inspired (and continues to inspire) a range of scholars, who have moved beyond the initial focus on media workers per se while retaining the concern with the mediation of production and consumption (if losing sight of the stratification of bourgeois and petite bourgeois fractions). Cultural economic analyses of cultural intermediaries continue to foreground the 'relational work' (Cochoy 2003 in du Gay 2004: 100) that goes on between production and consumption, while historicizing Bourdieu's account and pursuing empirically-grounded assessments of the devices, dispositions, impacts and limitations involved in a range of occupations. There are, therefore, tensions and synergies that remain between Bourdieusian and cultural economic perspectives on, and definitions of, cultural intermediaries. Looking more closely at the activities and outputs of cultural intermediaries, there is a room for developing a greater sense of: the formation of occupational dispositions, through education, professionalization, class habitus, and so forth; the articulation and negotiation of tensions that arise between objective credentials and subjective dispositions in the performance of authority; the tension between formal strategies and informal tactics employed in bringing goods to, and contextualizing goods for, the market; and the ways in which cultural intermediaries identify (with) and represent an intended market.

The focus on case studies has added much to our knowledge, but the body of research on cultural intermediaries has yet to develop a comparative element (at the level of research design, as opposed to an evident comparative element in the analysis of case study findings and reviews of literature). New comparative research would move us closer to grasping the materiality of what Cronin (2004) describes as the 'regimes of mediation.' Examinations of the ecology within commodity chains could assess the relative status and interconnections of cultural intermediaries operating within the same, and across cultural fields. In the same way, much would be gained from cross-cultural comparisons of cultural intermediaries operating within the same field, and cross-field comparisons of cultural intermediaries operating at comparable positions in the commodity chain (calling attention to the relative universality or (cultural or field) specificity of particular forms of value and their production). Additionally, comparisons of cultural intermediaries operating in the same field could also be made of those working with goods that occupy different status positions (calling attention to the question of autonomy for those working with goods of restricted production compared with those working with goods of mass 
production). Thus, the examination of the interconnections between cultural intermediaries and the media remains a fertile field, with much work to be done.

\section{References}

Amin, Ash and Thrift, Nigel. (eds.) 2004.The Blackwell Cultural Economy Reader. Oxford: Blackwell.

Bourdieu, Pierre. 1984. Distinction: A Social Critique of the Judgment of Taste. Cambridge, MASS: Harvard University Press.

Bourdieu, Pierre. 1996. The Rules of Art. Cambridge: Polity Press.

Bourdieu, Pierre, Boltanski, Luk, Castel, Robert and Chamboredon, Jean-Claude. 1990. Photography: A Middle-brow Art. Cambridge: Polity.

Bourdieu, Pierre and Passeron, Jean-Claude. 1977. Reproduction in Education, Society and Culture. London: Sage.

Caldwell, John. 2008. Production Culture: Industrial Reflexivity and Critical Practice in Film and Television. Durham: Duke University Press.

Callon, Michel, Méadel, Cécile and Rabeharisoa, Vololona. 2002. "The Economy of Qualities." Economy and Society 31(2): 194-217.

Campbell, Colin. 1987. The Romantic Ethic and the Spirit of Modern Consumerism. New York: Blackwell.

Cook, Dan. 2006. "In Pursuit of the 'Inside View': Training the Research Gaze on Advertising and Market Practitioners." Pp. 534-46. in Russell Belk (ed.) Handbook of Qualitative Research Methods in Marketing, Cheltenham: Edward Elgar Publishing.

Crewe, Ben. 2003. Representing Men: Cultural Production and Producers in the Men's Magazine Market. Oxford: Berg.

Cronin, Anne M. 2004. "Regimes of Mediation: Advertising Practitioners as Cultural Intermediaries?" Consumption, Markets and Culture 7(4): 349-69.

D’Acci, Julie. 1994. Defining Women: The Case of Cagney and Lacey. Chapel Hill: University of North Carolina Press.

Davila, Arlene. 2001. Latinos, Inc. Berkeley: University of California Press. du Gay, Paul. 2004. "Devices and Dispositions: Promoting Consumption." Consumption, Markets and Culture, 7(2): 99-105.

du Gay, Paul, Hall, Stuart, Janes, Linda, Mackay, Hugh and Negus, Keith. 1997. Doing Cultural Studies: The Story of the Sony Walkman. London: Sage.

du Gay, Paul and Pryke, Michael. 2002. "Cultural Economy: An Introduction.” Pp. 1-19. in Paul du Gay and Michael Pryke (eds.) Cultural Economy: Cultural Analysis and Commercial Life. London: Sage.

Entwistle, Joanne. 2006. "The Cultural Economy of Fashion Buying." Current Sociology 54: 704-24.

Featherstone, Mike. 1991. Consumer Culture and Postmodernism. London: Sage. Florida, Richard. 2002. The Rise of the Creative Class. New York: Basic Books.

Foucault, Michel. 1991. "Governmentality.” Pp. 87-104. in Graham Burchell, Colin Gordon and Peter Miller (eds.) The Foucault Effect: Studies in Governmentality. Chicago: University of Chicago Press.

Garnham, Nicholas. 2005. "A Personal Intellectual Memoir." Media, Culture \& Society, 27(4): 469-93. 
Gough-Yates, Anna. 2003. Understanding Women's Magazines. London: Routledge. Havens, Timothy. 2006. Global Television Marketplace. London: BFI.

Havens, Timothy, Lotz, Amanda D., and Tinic, Serra. 2009. "Critical Media Industry Studies: A Research Approach.” Communication, Culture \& Critique 2: 234-53.

Hesmondhalgh, David. 2006. "Bourdieu, the Media and Cultural Production." Media, Culture \& Society, 28(2): 211-31.

Lash Scott and Urry John. 1994. Economies of Signs and Space. London: Sage.

Lotz, Amanda D. 2007. "How to spend \$9.3 billion in three days: Examining the upfront buying process in the production of US television culture." Media, Culture \& Society, 29(4): 549-67.

McCracken, Grant. 1988. Culture and Consumption: New Approaches to the Symbolic Character of Consumer Goods and Activities. Bloomington, IN: Indiana University Press.

McFall, Liz. 2002. "Who Were the Old Cultural Intermediaries?: An Historical Review of Advertising Producers." Cultural Studies, 16(4): 532-552.

McFall, Liz. 2004. Advertising: A Cultural Economy. London: Sage.

McKay, Susan. 2008. "Advice Columns as Cultural Intermediaries." Australian Journal of Communication, 35(3): 93-103.

Mellor, Noha. 2008. "Arab Journalists as Cultural Intermediaries." The International Journal of Press/Politics, 13(4): 465-83.

Miller, Peter and Rose, Nikolas. 1997. "Mobilizing the Consumer: Assembling the Subject of Consumption." Theory, Culture \& Society 14(1): 1-36.

Moeran, Brian. 1996. A Japanese Advertising Agency: An Anthropology of Media and Markets. Curzon/Hawaii University Press.

Moor, Liz. 2008. "Branding Consultants as Cultural Intermediaries." The Sociological Review 56(3): 408-28.

Negus, Keith. 2002. "The Work of Cultural Intermediaries and the Enduring Distance Between Production and Consumption." Cultural Studies, 16(4): 50115.

Nixon, Sean. 2003. Advertising Cultures: Gender and Creativity at Work in Advertising, Sage

Nixon, Sean and Crewe, Ben. 2004. "Pleasure at Work?: Gender, Consumption and Work-Based Identities in the Creative Industries." Consumption, Markets and Culture 7(2): 129-47.

Nixon, Sean and du Gay, Paul. 2002. "Who Needs Cultural Intermediaries?" Cultural Studies, 16(4): 495-500.

Pettinger, Lynne. 2004. "Brand Culture and Branded Workers: Service Work and Aesthetic Labour in Fashion Retail." Consumption, Markets and Culture 7(2): 165-84.

Rocamora, Agnes. 2002. "Fields of Fashion: Critical Insights into Bourdieu's Sociology of Culture." Journal of Consumer Culture 2(3): 341-62.

Sender, Katherine. 2004. Business, Not Politics: The Making of the Gay Market. New York: Columbia University Press.

Skov, Lise. 2002. "Hong Kong Fashion Designers as Cultural Intermediaries: Out of Global Garment Production.” Cultural Studies 16(4): 553-569. 
Smith Maguire, Jennifer. 2008. "The Personal is Professional: Personal Trainers as a Case Study of Cultural Intermediaries." International Journal of Cultural Studies 11(2): 203-221.

Soar, Matthew. 2000. "Encoding Advertisements: Ideology and Meaning in Advertising Production." Mass Communication \& Society 3(4): 415-37.

Tinic, Serra. 2005. On Location: Canada's Television Industry in a Global Market. Toronto: University of Toronto Press.

Wright, David. 2005. "Mediating Production and Consumption: Cultural Capital and "Cultural Workers." British Journal of Sociology 56(1): 105-21.

Zwick, Detlev, Bonsu, Samuel K. and Darmody, Aron. 2008. "Putting Consumers to Work: 'Co-creation' and New Marketing Govern-mentality." Journal of Consumer Culture 8(2): 163-96. 